\title{
VEDAÇÃO DA TERCEIRIZAÇÃO DA ATIVIDADE FINALIISTICA EDUCACIONAL NO ENSINO SUPERIOR
}

\author{
SEALING OF THIRD PARTNERSHIP OF \\ EDUCATIONAL FINAL ACTIVITY IN HIGHER EDUCATION
}

lara Marthos ÁGUILA ${ }^{1}$

Camila da Silva ALENCAR ${ }^{2}$

ISSUE DOI: $10.21207 / 1983.4225 .834$

\begin{abstract}
RESUMO
O presente artigo aborda os principais aspectos da terceirização da prestação de serviços e as mudanças sobre a abrangência da terceirização determinadas pela Lei $n^{\circ}$ 13.429/2017 e pela Lei $n^{\circ} 13.467 / 2017$, e consequente ampliação das possibilidades de contratação de empresas prestadoras de serviços independente da atividade desenvolvida pela contratante. Em sentido contrário, o Decreto ${ }^{\circ} 9.235$, publicado em 18 de dezembro de 2017, apresenta importante limitação ao processo de terceirização vedando sua utilização no caso de atividade finalística educacional no ensino superior. Necessário, portanto, compreender o conceito de atividadefim e as atividades que estão inseridas no âmbito educacional, qual sejam, a atividade de lecionar, educar, enfim, a atividade docente realizada em Instituição de Ensino, seja pública ou particular. Nesse sentido, a docência está diretamente ligada à garantia de educação, prevista no artigo 205 da Constituição Federal. Considerando as implicações que a terceirização causaria na esfera educacional, serão levantados os principais benefícios trazidos pelo Decreto $\mathrm{n}^{\circ}$ 9.235/2017, no sentido de vedar a terceirização na prestação de serviços no âmbito educacional no ensino superior.
\end{abstract}

Palavras-chave: Dumping social; Vedação da terceirização; Atividade finalística educacional.

\footnotetext{
${ }^{1}$ Doutoranda em Direito pela pela Faculdade Autônoma de Direito (FADISP). Possui graduação em Direito pela Universidade Estadual Paulista Júlio de Mesquita Filho (1990) e mestrado em Direito pela Universidade Estadual Paulista Júlio de Mesquita Filho (1998). Atualmente é professora titular da Faculdade de Direito de Franca. Foi professora titular da Universidade de Franca e professora celetista na Universidade Estadual Paulista - Unesp, campus de Franca. Tem experiência na área de Direito, com ênfase em Direito do Trabalho. É advogada trabalhista atuante. http://lattes.cnpq.br/ 0671409528318178 .

${ }^{2}$ Advogada e especialista em Direito do Trabalho. Contato: camila.alencar@outlook.com. http://lattes.cnpq.br/3349394953216753.
} 


\begin{abstract}
This article discusses the main aspects of outsourcing of services and the changes in the scope of outsourcing determined by Law No. 13.429/2017 and Law No. 13.467 /2017, and consequent expansion of the possibilities of hiring service providers independent of the Company. activity developed by the contractor. Conversely, Decree No. 9,235, published on December 18, 2017, has an important limitation to the outsourcing process, prohibiting its use in the case of educational final activity in higher education. Therefore, it is necessary to understand the concept of core activity and the activities that are inserted in the educational field, namely, the activity of teaching, educating, finally, the teaching activity performed in a teaching institution, whether public or private. In this sense, teaching is directly linked to the guarantee of education, as foreseen in article 205 of the Federal Constitution. Considering the implications that outsourcing would have on the educational sphere, the main benefits brought by Decree No. 9,235 / 2017 will be raised, in order to prohibit outsourcing in the provision of educational services in higher education.
\end{abstract}

Keywords: Social dumping; Outsourcing seal; Educational Finalistic Activity.

\title{
INTRODUÇÃO
}

A terceirização da prestação de serviços é instituto jurídico há muito tempo utilizado nas relações jurídicas desenvolvidas no Brasil, no entanto, por falta de regulamentação legal expressa sobre o tema o Tribunal Superior do Trabalho (TST) adotou entendimento enunciado na Súmula $\mathrm{n}^{\circ}$ 331 que limita a possibilidade de terceirização válida apenas nas atividades relacionadas à atividade-meio do tomador de serviços e estabelece outras regras e consequências para a terceirização.

A Lei ${ }^{\circ} 13.429 / 2017$ e a Lei no $13.467 / 2017$, esta última identificada por Reforma Trabalhista, passaram a regulamentar a terceirização da prestação de serviços e estabeleceram novos e diferentes parâmetros para utilização do instituto da terceirização, alterando a Lei no 6.019/74. A Reforma Trabalhista autorizou a terceirização irrestrita das atividades empresariais, incluindo a atividade principal da contratante, ou seja, a atividade-fim passou a ser passível de terceirização. Embora o contratante legalmente possa ser pessoa física ou jurídica, o usual é ser o contratante uma empresa.

A trajetória histórica da terceirização no Brasil demonstra como o instituto foi ampliado e ganhou força com o tempo em razão da necessidade da empresa se adaptar ao mercado, com o intuito de resistir às crises econômicas do país.

O novo texto legal ampliou significativamente o alcance e utilização da contratação de empresas prestadoras de serviços. Evidente que a 
mudança de paradigma causou e causa apaixonadas discussões jurídicas sobre os reflexos do alcance das novas normas legais.

Em sentido contrário à possibilidade irrestrita de terceirização, em 18 de dezembro de 2017 (data posterior à entrada em vigor da Lei $n^{\circ}$ 13.467/2017) foi publicado o Decreto $n^{\circ}$ 9.235/2017 que, em seu artigo 72, inciso IV, veda a terceirização da atividade finalística educacional na oferta de ensino superior pelas Instituições de Ensino Superior (IES). A vedação traz diversos benefícios para a qualidade da educação, mantendo a atividade docente diretamente vinculada às Instituições de Ensino Superior.

No que tange à terceirização da prestação de serviços, a Reforma Trabalhista deverá alterar grande parte da organização empresarial do país, no entanto, muitos defendem que certas mudanças, inclusive a contratação de empresas prestadoras de serviços em substituição à própria atividade da contratante (terceirização) provocam a precarização das relações de trabalho, causando retrocesso nas conquistas dos trabalhadores brasileiros, impactando diretamente dos direitos trabalhistas.

Por outro lado, possível entender a necessidade de mudanças na organização empresarial visando a sobrevivência da empresa e consequente manutenção de empregos, ou mesmo a adequação da atividade empresarial em um novo contexto socioeconômico, com novas tecnologias usadas no modelo de produção. Entretanto, algumas atividades não são passíveis de terceirização, como é o caso da atividade educacional, que está diretamente ligada ao direito à educação previsto na Constituição Federal, esfera de suma importância para o desenvolvimento do país, conforme será abordado.

\section{A TERCEIRIZAÇÃO NO BRASIL}

O instituto da terceirização consiste, em suma, na transferência das atividades da contratante à terceiros especializados, que são responsáveis pela contratação dos empregados que prestarão serviços para a contratante, também denominada tomadora de serviços.

O intuito desta ferramenta no universo empresarial é diminuir custos da produção e tornar a atividade mais dinâmica, com isso, são inevitáveis as implicações na área trabalhista, previdenciária e até fiscal. A utilização de mão de obra especializada para determinados tipos de serviços - inexistindo pessoalidade e subordinação direta - diminui as despesas 
com folha de pagamento da empresa contratante, que dá mais disposição financeira para investimentos e crescimento econômico, nesse sentido, Alice Monteiro de Barros descreve:

Teoricamente, o objetivo da terceirização é diminuir os custos e melhorar a qualidade do produto ou do serviço. Alguns especialistas denominam esse processo de "especialização flexível", ou seja, aparecem empresas, com acentuado grau de especialização em determinado tipo de produção, mas com capacidade para atender a mudanças de pedidos de seus clientes. ${ }^{3}$

Com o mesmo entendimento, antes da Reforma Trabalhista, Sergio Pinto Martins definiu a terceirização nos termos abaixo:

Consiste a terceirização na possibilidade de contratar terceiro para a realização de atividades que não constituem o objeto principal da empresa. Essa contratação pode compreender tanto a produção de bens, como de serviços, como ocorre na necessidade de contratação de empresa de limpeza, de vigilância ou até para serviços temporários. $^{4}$

De forma sucinta, Arnaldo Süssekind acrescenta quanto ao conceito da terceirização: "O fenômeno da transferência da produção de bens ou serviços para outra empresa ou pessoa que não aquela que, primitivamente, os produzia". 5

Legalmente a terceirização surgiu no Brasil com a entrada em vigor da Lei ${ }^{\circ}$ 6.019/74, que trouxe as primeiras hipóteses de autorização para terceirizar serviços: (i) para atender à necessidade transitória de substituição de seu pessoal regular e permanente ou (ii) à acréscimo extraordinário de serviços. ${ }^{6}$

Após, o Tribunal Superior do Trabalho editou a Súmula $n^{\circ} 256$, já cancelada, que previa a legalidade de contratação de empregados por meio de empresa interposta nas hipóteses de trabalho temporário e para os serviços de vigilância.

Durante a vigência da referida Súmula, qualquer tipo de terceirização que não se enquadrasse nas exceções previstas, era considerada ilegal e o vínculo empregatício direto com a empresa tomara dos serviços era reconhecido.

\footnotetext{
${ }^{3}$ BARROS, Alice Monteiro de. Curso de direito do trabalho. 10. ed. - São Paulo: LTr, 2016. p. 300.

${ }^{4}$ MARTINS, Sergio Pinto. Direito do trabalho. 30. ed. - São Paulo: Atlas, 2014. p. 207.

${ }^{5}$ SUSSEKIND, Arnaldo. Instituições do direito do trabalho. 21. ed. Vol I. Editora LTr, 2003. p. 277.

${ }^{6}$ Artigo $2^{\circ}$ da Lei 6.019/1974 alterado pela Lei ${ }^{\circ} 13.429$, de 2017.
} 
Posteriormente, o TST editou a Súmula n ${ }^{o} 331$, que ampliou as possibilidades de terceirização para todas as atividades vinculadas à atividade-meio da empresa tomadora de serviços, ou seja, a atividade que não integra o trabalho finalístico da empresa, atividades que não participam ou se relacionam com seu objetivo final, com a atividade-fim da empresa contratante. ${ }^{7}$ A Súmula 256 foi cancelada.

A Lei $n^{\circ} 13.429 / 2017$ (publicada em 31/03/2017) alterou a Lei $n^{\circ}$ 6.019/74 e trouxe regulamentação legal para a contratação de empresas prestadoras de serviço à terceiros (terceirização). Em 11/11/2017 entrou em vigor a Lei $n^{\circ} 13.467 / 2017$ (Reforma Trabalhista) que novamente alterou a Lei $n^{\circ}$ 6.019/74 e explicitou a ampliação da possibilidade de terceirização para todas as atividades empresariais, inclusive a atividade-fim do contratante. Além da citada ampliação o instituto da terceirização foi regulamentado em vários outros aspectos.

A Súmula $n^{\circ} 331$ do TST ainda não foi cancelada, no entanto, como será abordado adiante, a limitação da terceirização às atividadesmeio da empresa tomadora não se sustenta juridicamente em razão da atual redação da Lei n 6.019/74.

Dessa forma, pela breve abordagem histórica realizada, é possível notar a grande expansão da terceirização no Brasil, mecanismo que retira da empresa tomadora a responsabilidade principal de arcar com o pagamento das verbas trabalhistas dos empregados terceirizados, sendo estes empregados contratados e remunerados pela empresa prestadora de serviços, conforme será esclarecido a seguir.

\footnotetext{
${ }^{7}$ Súmula 331 do TST: CONTRATO DE PRESTAÇÃO DE SERVIÇOS. LEGALIDADE (nova redação do item IV e inseridos os itens V e VI à redação) - Res. 174/2011, DEJT divulgado em 27, 30 e 31.05.2011. I - A contratação de trabalhadores por empresa interposta é ilegal, formando-se o vínculo diretamente com o tomador dos serviços, salvo no caso de trabalho temporário (Lei $\mathrm{n}^{\circ}$ 6.019, de 03.01.1974). II - A contratação irregular de trabalhador, mediante empresa interposta, não gera vínculo de emprego com os órgãos da Administração Pública direta, indireta ou fundacional (art. 37, II, da $\mathrm{CF} / 1988$ ). III - Não forma vínculo de emprego com o tomador a contratação de serviços de vigilância (Lei $\mathrm{n}^{\circ}$ 7.102, de 20.06.1983) e de conservação e limpeza, bem como a de serviços especializados ligados à atividade-meio do tomador, desde que inexistente a pessoalidade e a subordinação direta. IV - O inadimplemento das obrigações trabalhistas, por parte do empregador, implica a responsabilidade subsidiária do tomador dos serviços quanto àquelas obrigações, desde que haja participado da relação processual e conste também do título executivo judicial. V - Os entes integrantes da Administração Pública direta e indireta respondem subsidiariamente, nas mesmas condições do item IV, caso evidenciada a sua conduta culposa no cumprimento das obrigações da Lei n. ${ }^{\circ} 8.666$, de 21.06.1993, especialmente na fiscalização do cumprimento das obrigações contratuais e legais da prestadora de serviço como empregadora. A aludida responsabilidade não decorre de mero inadimplemento das obrigações trabalhistas assumidas pela empresa regularmente contratada. VI - A responsabilidade subsidiária do tomador de serviços abrange todas as verbas decorrentes da condenação referentes ao período da prestação laboral.
} 


\section{$2.1 \quad$ RESPONSABILIDADE TRABALHISTA}

Até pouco tempo atrás a terceirização da prestação de serviços no Brasil era vista pelo Judiciário Trabalhista como uma forma de burlar os direitos trabalhistas dos empregados. Em diversos casos a Justiça do Trabalho visualizava apenas simulação na utilização do instituto, nessa vertente, Wilson Alves Polônio afirma:

A simulação, no processo de terceirização visa, quase sempre, burlar a lei com o objetivo de reduzir os encargos tributários incidentes na relação empregatícia, notadamente os encargos devidos à seguridade social. O trabalhador, não obstante seja parte na relação contratual dissimulada, também resta prejudicado neste processo, de vez que tem seus ganhos representados pelos encargos trabalhistas ( $13^{\circ}$ salário, férias, descanso semanal remunerado, Fundo de Garantia por tempo de serviço (FGTS), participação nos lucros da empresa etc.) reduzidos ou totalmente extintos $(\ldots) .{ }^{8}$

\section{Constatada a simulação, o vínculo empregatício com a empresa tomadora era reconhecido. Assim decidiu o TST em 2013:}

VÍNCULO DE EMPREGO. EMPRESA DE TELECOMUNICAÇÕES. HIPÓTESE DE CONTRATAÇÃO MEDIANTE COOPERATIVA. FRAUDE. TERCEIRIZAÇÃO ILÍCITA. SUBORDINAÇÃO DIRETA À TOMADORA DOS SERVIÇOS. 1. Constatando-se que o reclamante foi contratado mediante cooperativa considerada fraudulenta, não há falar em terceirização lícita nos moldes da Lei Geral das Telecomunicações - Lei n. ${ }^{\circ}$ 9.472/97. 2. Consoante disposto na Súmula . $^{\circ}$ 331, itens I e III, desta Corte superior, a terceirização ilícita de serviços, caracterizada pela contratação de serviços ligados à atividade-fim mediante empresa interposta ou pela contratação de serviços especializados ligados à atividade-meio, mas prestados com pessoalidade e subordinação direta ao contratante, acarreta o reconhecimento de vínculo de emprego diretamente com o tomador dos serviços. 3. Uma vez consignado expressamente no acórdão prolatado pelo Tribunal Regional que o reclamante prestava serviços de forma exclusiva, relacionada à atividade fim da TELEMAR - tomadora dos serviços -, resulta evidenciada a ilicitude da terceirização havida, visto que configurado o intuito de fraudar a legislação trabalhista mediante a contratação do obreiro por intermediação de cooperativa simulada. Em tais circunstâncias, o vínculo de emprego forma-se diretamente com a tomadora dos serviços, nos termos do verbete sumular transcrito. 4. Revelando a decisão recorrida sintonia com a jurisprudência pacífica do Tribunal Superior do Trabalho, não se habilita a processamento o recurso de revista, nos termos do artigo $896, \S 5^{\circ}$, da Consolidação das Leis do Trabalho. 5. Agravo de instrumento a que

\footnotetext{
${ }^{8}$ POLONIO, Wilson Alves. Terceirização: aspectos legais, trabalhistas e tributários. São Paulo: Atlas, 2000. p. 108.
} 
se nega provimento. (AIRR - 85540-19.2005.5.01.0024, Relator Ministro: Lelio Bentes Corrêa, Data de Julgamento: 08/05/2013, $1^{\text {a }}$ Turma, Data de Publicação: DEJT 17/05/2013)

Em razão da grande quantidade de fraudes comprovadamente ocorridas envolvendo a terceirização, inegável a necessidade de responsabilização da empresa tomadora de serviços, em face da evidente falta de isenção da empresa tomadora, que não raras vezes atua de forma negligente na contratação da empresa interposta. No intuito de garantir os direitos trabalhistas dos empregados das empresas prestadoras de serviços foi adotada a responsabilidade subsidiária da empresa contratante.

O princípio da proteção ao trabalhador permite imputar responsabilidade subsidiária ${ }^{9}$ à empresa tomadora dos serviços, se eventualmente a empresa interposta restar inadimplente, uma vez que os serviços prestados pelo empregado se reverteram em benefício econômico da contratante.

No mesmo sentido, a empresa tomadora dos serviços assume o risco pela contratação dos empregados terceirizados, independente de eventual má-fé ou culpa, sendo clara sua responsabilidade em caso de inadimplência do parceiro, assim esclarece Alice Monteiro de Barros:

\footnotetext{
O risco traduz uma objetivação da responsabilidade, garantida com o fim de assegurar uma proteção jurídica à pessoa humana, "em particular aos trabalhadores e às vítimas de acidentes, contra a insegurança material e todo dano deve ter um responsável. A noção de risco prescinde da prova da culpa do lesante, contentando-se com a simples causação externa, bastando a prova de que o evento decorreu do exercício da atividade, para que o prejuízo por ela criado seja indenizado. Baseia-se no princípio do ubi emolumentum, ibi ius (ou ibi ônus), isto é, a pessoa que se aproveitar dos riscos ocasionados deverá arcar com suas consequências. ${ }^{10}$
}

Em resumo, a relação empregatícia do trabalhador terceirizado se dá com a empresa prestadora de serviços à terceiros, que o contrata e se obriga por todos os direitos trabalhistas. Por outro lado, a empresa prestadora de serviços celebra contrato de natureza civil com a empresa tomadora de serviços (contratante) para fornecer serviço determinado.

\footnotetext{
${ }^{9}$ Art. $5^{\circ}$-A, da Lei ${ }^{\circ} 6.019 / 74$, no caput estabelece que: Contratante é a pessoa física ou jurídica que celebra contrato com empresa de prestação de serviços relacionados a quaisquer de suas atividades, inclusive sua atividade principal (Redação dada pela Lei $\mathrm{n}^{\circ} 13.467$, de 2017). O § $5^{\circ}$ do mesmo artigo prevê que: A empresa contratante é subsidiariamente responsável pelas obrigações trabalhistas referentes ao período em que ocorrer a prestação de serviços, e o recolhimento das contribuições previdenciárias observará o disposto no art. 31 da Lei no 8.212, de 24 de julho de 1991.

${ }^{10}$ BARROS, Alice Monteiro de. Curso de direito do trabalho. 10. ed. - São Paulo: LTr, 2016. p. 301.
} 
A empresa tomadora, por sua vez, fica desonerada de aumentar sua folha de pagamento e aproveita os serviços prestados pelo terceirizado. Portanto, em caso de eventual condenação trabalhista, responde de forma subsidiária pelo pagamento, se assemelhando a um fiador ou avalista da relação empregatícia firmada com a empresa prestadora de serviços.

\section{A REFORMA TRABALHISTA E A ABRANGÊNCIA DA TERCEIRIZAÇÃO}

Até a entrada em vigor da Lei n ${ }^{\circ} 13.429 / 2017$ a terceirização da prestação de serviços era validada pelo TST apenas para atividades-meio da empresa contratante. Esta limitação foi retirada no novo texto legal que, portanto, ampliou a abrangência da terceirização com a retirada da restrição prevista no inciso III, da Súmula no 331 do TST. Até o momento não houve o cancelamento da mencionada súmula, contudo, salvo melhor juízo, a manutenção da súmula representa afronta direta ao texto de lei federal, razão pela qual, o cancelamento se impõe.

Nos termos do artigo $4^{\circ}$-A, da Lei $n^{\circ} 6.019 / 74^{11}$, a terceirização foi autorizada de forma irrestrita, independentemente da atividade desenvolvida pelo contratante, e igualmente, independente da natureza do serviço prestado pela empresa prestadora de serviços, podendo coincidir com a atividade-fim da empresa tomadora de serviços. No mesmo sentido está o disposto no caput do artigo $5^{\circ}-\mathrm{A}^{12}$, do mesmo diploma legal.

A alteração trazida pela Reforma Trabalhista e que modificou o texto da Lei $\mathrm{n}^{\circ} 6.019 / 74$, a princípio poderia ser questionada quanto à sua aplicação generalizada, tendo em vista que referida lei é específica para regulamentar o trabalho temporário disponibilizado por empresas de trabalho temporário, de modo que, era possível questionar a aplicabilidade da

\footnotetext{
${ }^{11}$ Art. 4ㅇ-A. Considera-se prestação de serviços a terceiros a transferência feita pela contratante da execução de quaisquer de suas atividades, inclusive sua atividade principal, à pessoa jurídica de direito privado prestadora de serviços que possua capacidade econômica compatível com a sua execução.

${ }^{12}$ Art. 5--A. Contratante é a pessoa física ou jurídica que celebra contrato com empresa de prestação de serviços relacionados a quaisquer de suas atividades, inclusive sua atividade principal.
} 
nova legislação, quanto à limitação aos trabalhadores temporários ${ }^{13}$, no entanto, esta não foi a intenção do legislador, que de fato almejou a total ampliação do instituto.

Em razão dos novos dispositivos legais, surgiu a dúvida sobre a real abrangência da terceirização quanto à atividade-fim da contratante, uma vez que a mudança foi realizada na lei que trata do trabalho temporário, sendo, por consequência, aplicada apenas a esta categoria.

De fato, havia parte da doutrina que defendia tal limitação, contudo, trata-se de interpretação superada por decisão do Supremo Tribunal Federal (STF) sobre terceirização, decidindo pela constitucionalidade da irrestrita terceirização da atividade finalística da contratante dos serviços terceirizados. Nas palavras do Ministro Luís Roberto Barroso:

\begin{abstract}
Direitos básicos não podem ser afastados - piso salarial, segurança no trabalho, férias, fundo de garantia. Tudo isso são direitos fundamentais assegurados e não estão em discussão aqui. [...]. A questão é saber se é bom para negócio que atividades sejam prestadas pelo terceiro. Isso não é direito, isso é economia, não há como fugir desse modelo. O modelo de produção flexível é realidade em todo o mundo. ${ }^{14}$
\end{abstract}

Como já exposto acima, o termo terceirização se refere à contratação de empresa para prestação de serviços à tomadora, trata-se de uma subcontratação, com o fim de diminuir custos da contratante e melhorar a qualidade do produto ou serviço, por ser fornecido por empresa especializada. Para sua configuração, necessária a ausência de subordinação e pessoalidade dos empregados da empresa terceirizada para com a empresa tomadora, sob pena de reconhecimento de vínculo de emprego direto com a empresa tomadora e também a configuração de fraude, com a aplicação das devidas penalidades.

Na terceirização forma-se uma relação jurídica triangular, sendo integrantes a empresa tomadora dos serviços (também denominada contratante), a empresa especializada prestadora dos serviços, e o empregado terceirizado (contratado pela prestadora de serviços).

\footnotetext{
${ }^{13}$ TOLEDO FILHO. Manoel Carlos. Nova lei impede terceirização permanente da atividade-fim. Disponível em: https://www.anamatra.org.br/artigos/25167-nova-lei-impede-terceirizacao-permanenteda-atividade-fim. Acesso em 22 ago. 2018.

${ }^{14}$ OLIVEIRA, Mariana e BARBIÉRI, Luiz Felipe, TV Globo e G1, Brasília 22/08/2018 17h48. Relatores no STF, Barroso e Fux votam por liberar terceirização em atividades-fim Disponível em: https://g1.globo.com/ politica/noticia/2018/08/22/relator-no-stf-barroso-vota-por-liberar-terceirizacao-em-atividade-fim.ghtml. Acesso em 23 ago. 2018.
} 
A nova redação do artigo $4^{\circ}-\mathrm{A}^{15}$, da Lei $\mathrm{n}^{\circ} 6.019 / 74$ permite à própria empresa prestadora de serviços contratar outra empresa para oferta dos serviços, portanto, é possível com os novos dispositivos legais que a conhecida terceirização seja composta por mais de três partes, sem limitações. Sendo assim, a empresa prestadora de serviços pode repassar suas obrigações para outra empresa especializada, ou seja, a prestadora de serviços terceirizada pode não ser a empregadora dos empregados terceirizados, alcançando-se o fenômeno da quarteirização.

De acordo com Dias ${ }^{16}$ a quarteirização consiste na prestação de serviços por uma quarta empresa, que gerencia os funcionários terceirizados, oferecendo todo o suporte necessário para organização e facilitação da gestão dos setores.

Assim, no mesmo sentido do voto vencedor no STF sobre a constitucionalidade da terceirização da atividade-fim do contratante ou tomador de serviços, difícil a sustentação da limitação do alcance da nova legislação, devido a realidade econômica do país, que precisa se adaptar aos novos modelos de contratação para sobreviver no mercado e não onerar as empresas.

\section{4 \\ A VEDAÇÃO DA TERCEIRIZAÇÃO DA ATIVIDADE FINALÍSTICA EDUCACIONAL PREVISTA NO DECRETO № 9.235/2017}

O Decreto $n^{\circ}$ 9.235/2017 dispõe sobre o exercício das funções de regulação, supervisão e avaliação das Instituições de Educação Superior (IES). As seções III, IV e VIII (credenciamento e recredenciamento institucional, autorização de abertura de cursos) do capítulo II do referido decreto tratam do pedido de credenciamento das IES privadas junto ao Ministério da Educação e estabelecem uma série de requisitos totalmente incompatíveis com a possibilidade de terceirização da prestação de serviços

\footnotetext{
${ }^{15}$ Art. $4^{\circ}$-A. Considera-se prestação de serviços a terceiros a transferência feita pela contratante da execução de quaisquer de suas atividades, inclusive sua atividade principal, à pessoa jurídica de direito privado prestadora de serviços que possua capacidade econômica compatível com a sua execução. § $1^{\circ}$ A empresa prestadora de serviços contrata, remunera e dirige o trabalho realizado por seus trabalhadores, ou subcontrata outras empresas para realização desses serviços. (Incluído pela Lei nº 13.429 , de 2017).

${ }^{16}$ Apud MENDONÇA, A.S. et al. Aspectos gerais da terceirização e quarteirização: um estudo com funcionários terceirizados. Revista acadêmica da Faculdade Fernão Dias, Osasco, n. 11, p. 1-22, fev. 2017.
} 
docentes, via de consequência, terceirização da atividade fim das IES, vale dizer, prestação de serviços educacionais, presencial ou à distância.

Embora o texto do decreto fosse suficiente para demonstrar a incompatibilidade da atividade educacional com a terceirização, o artigo $72^{17}$, do Decreto $n^{\circ} 9.235 / 2017$, expressamente proíbe a terceirização de atividade finalística educacional, considerando a prática como uma irregularidade administrativa das IES, passível de penalidades.

\subsection{A ATIVIDADE FINALÍSTICA EDUCACIONAL}

Antes de adentrar à finalidade específica educacional, importante abordar a definição da atividade-fim da empresa, sempre muito citada nos julgados que até 2017 causariam a condenação da empresa tomadora de serviços. Nesse sentido, ao julgar uma ação trabalhista ${ }^{18}$ o TST conceituou atividade-fim, nos seguintes termos: "As atividades-fim podem ser conceituadas como as funções e tarefas empresariais e laborais que se ajustam ao núcleo da dinâmica empresarial do tomador de serviços, compondo a essência dessa dinâmica e contribuindo inclusive para a definição de seu posicionamento e classificação no contexto empresarial e econômico."

A atividade-fim, portanto, é aquela relacionada à finalidade da empresa, atividades que integram o núcleo da dinâmica empresarial, relacionada ao objetivo da empresa tomadora, a título de exemplo, possível citar a atividade de lecionar, dentro de uma Instituição de Ensino, ou seja, a atividade exercida pelo seu corpo docente.

Desse modo, a atividade finalística educacional é o objetivo final de uma Instituição de Ensino, pública ou privada, que consiste na oferta de educação através do ensinoaprendizagem, realizado pelos professores.

A jurisprudência pátria é pacífica ao reconhecer que a atividade finalística educacional é realizada pelo docente e, caso a empresa utilize meios fraudulentos para contratação indireta deste profissional, era, e, como será visto a seguir, ainda poderá ser punida por tal prática. Assim o TST demonstra no julgado abaixo:

\footnotetext{
${ }^{17}$ Art. 72. Serão consideradas irregularidades administrativas, passíveis de aplicação de penalidades, nos termos deste Decreto, as seguintes condutas: [...] IV - terceirização de atividade finalística educacional, sob quaisquer designações, na oferta de educação superior;

${ }^{18}$ ARR - 1037-89.2011.5.09.0652, Relator Ministro: Mauricio Godinho Delgado. Data de Julgamento: 10/09/2014, $3^{\text {a }}$ Turma, Data de Publicação: DEJT 03/10/2014.
} 
RECURSO DE REVISTA EM FACE DE DECISÃO PUBLICADA ANTES DA VIGÊNCIA DA LEI No 13.015/2014. COOPERATIVA. INTERMEDIAÇÃO FRAUDULENTA DE MÃODE-OBRA. RECONHECIMENTO DE VÍNCULO DE EMPREGO. MATÉRIA

FÁTICA. O e. Tribunal Regional registrou que o trabalhador prestou serviços para o Instituto nas funções de professor. Foi ressaltado que a prova dos autos demonstra a presença de todos os elementos fático-jurídicos que compõem a relação de emprego. A Corte a quo asseverou ainda que a contratação ocorreu "com vistas à utilização de mão-de-obra tipicamente empregatícia, sob as vestes de sistema cooperativado, no intuito de obter redução de custos, em evidente afronta aos direitos trabalhistas de tais pseudo-cooperados, que restaram prejudicados". O argumento recursal é no sentido de que não houve fraude na contratação do trabalhador. Nesse contexto, não prospera a denúncia de ofensa aos artigos $174, \S 2^{\circ}$, da Constituição da República; 442, parágrafo único, da CLT e 86 da Lei $n^{\circ} 5764 / 71$, uma vez que na hipótese dos autos foi descaracterizado o trabalho cooperado e evidenciado que a cooperativa teve o nítido intuito de fraudar direitos trabalhistas, sendo mera intermediadora de mão-de-obra para atividade-fim do tomador dos serviços. Ante a harmonia do acórdão regional com a Súmula 331, I, do TST, incide o óbice do artigo 896, $\S 4^{\circ}$, da CLT (Lei no 9.756/98). Acresça-se que a pretensão do recorrente também encontra óbice intransponível em súmula desta Corte, porquanto, para se confrontar o decisum regional com o argumento do Instituto seria necessária incursão no conjunto fático-probatório, circunstância vedada pela Súmula $\mathrm{n}^{\circ} 126$ do TST, que impede o reexame de fatos e provas nesta fase processual. Recurso de revista não conhecido. INTERMEDIAÇÃO FRAUDULENTA DE MÃO-DE-OBRA POR MEIO DE COOPERATIVA. DANO MORAL.

CARACTERIZAÇÃO. Ao contrário do decidido pelo TRT, em casos de terceirização irregular de mão-de-obra por meio de cooperativa interposta não há lugar para a condenação do contratante por danos morais. Não se olvida que a situação registrada pela Corte Regional configura uma reprovável conduta que tem o condão de macular os direitos da personalidade do trabalhador. Contudo, em casos de ausência de registro, registro fraudulento ou falta de pagamento de verbas, o ordenamento jurídico pátrio já prevê as cominações, que têm natureza penal e compensatória; acrescente-se ainda a previsão de correção monetária e juros da mora para os casos aqui citados. Nesse esteio, não se pode verificar conduta infringente dos direitos extrapatrimoniais do trabalhador, não se podendo qualificar a situação justificadora de imposição da condenação à reparação por danos morais. Por fim, registre-se que a constatação da terceirização irregular deve ser resolvida por intermédio da satisfação de todas as obrigações trabalhistas pertinentes à relação jurídica efetivamente mantida entre as partes ( $\operatorname{artigo} 9^{\circ}$ da CLT), existindo ainda a previsão de se reconhecer o vínculo de emprego diretamente com o tomador de serviços, como in casu. Dessa forma, o Tribunal Regional, ao condenar o ora recorrente ao pagamento de 
indenização por danos morais em face da terceirização por meio de cooperativa interposta, ofendeu dispositivos da legislação federal e da Constituição da República. Recurso de revista conhecido por violação dos artigos 186 do CCB e $5^{\circ}$, X, da Constituição da República.

HONORÁRIOS ADVOCATÍCIOS. REQUISITOS PARA O DEFERIMENTO.

ASSISTÊNCIA SINDICAL. NECESSIDADE. Na Justiça do Trabalho, a condenação em honorários advocatícios exige o preenchimento concomitante dos requisitos de que trata o art. 14 da Lei 5.584/70. Nesse sentido o item I da Súmula 219 do TST. No caso, ausente a assistência sindical, são indevidos os honorários. Recurso de revista conhecido por contrariedade à Súmula 219, I, do TST e provido. CONCLUSÃO: Recurso de revista parcialmente conhecido e provido. (RR - 27950091.2008.5.02.0060, Relator Ministro: Alexandre de Souza Agra Belmonte, Data de Julgamento: 13/09/2017, $3^{a}$ Turma, Data de Publicação: DEJT 15/09/2017)

Desta forma, restou esclarecido o objeto da atividade finalística educacional e o trabalhador responsável por exercê-la: o docente, que desde os primórdios, exerce a atividade de ensinar com pessoalidade (requisito legal que caracteriza a configuração do vínculo de emprego), para acompanhar o desenvolvimento educacional de seus alunos.

\subsection{DOS BENEFÍCIOS DA VEDAÇÃO DA TERCEIRIZAÇÃO DA ATIVIDADE-FIM EDUCACIONAL}

Conforme exposto anteriormente, em 31 de março de 2017 foi aprovada a Lei n ${ }^{\circ} 13.429$ que trouxe a ampliação da terceirização no Brasil, o instituto a partir de então também poderá ser utilizado para obtenção da atividade-fim da empresa, de forma irrestrita. Em novembro de 2017 entrou em vigor a Lei $\mathrm{n}^{\circ} 13.467$ que trouxe algumas alterações à lei anterior para explicitar inequivocamente a validade da terceirização em qualquer atividade empresarial, inclusive a atividade-fim. Em dezembro de 2017 entrou em vigor o Decreto $n^{\circ} 9.235$, que dispõe sobre o exercício das funções de regulação, supervisão e avaliação das instituições de educação superior e dos cursos superiores de graduação e de pós-graduação no sistema federal de ensino. 
Em referido Decreto, o artigo 72 faz constar expressamente a vedação da terceirização da atividade finalística educacional no ensino superior, sendo tal conduta considerada como uma irregularidade administrativa, passível de aplicação de penalidades previstas no artigo 73 do diploma legal.

A proibição instituída no Decreto $\mathrm{n}^{\circ}$ 9.235/2017 caminha em consonância com a Lei $n^{\circ}$ 9.394/1996 que estabeleceu as diretrizes e bases da educação nacional. $\mathrm{O}$ artigo $3^{\circ}$ da citada lei estabelece os princípios a serem seguidos para a forma de ensino. A vedação da terceirização da atividadefim educacional atende aos princípios indicados no texto legal e, dessa forma, continuarão sendo respeitados de maneira mais efetiva. Alguns princípios elencados no artigo $3^{\circ}$, da Lei $n^{\circ}$ 9.394/1996 revelam claramente a impossibilidade de terceirização da atividade docente:

Art. $3^{\circ} \mathrm{O}$ ensino será ministrado com base nos seguintes princípios:

$[\ldots]$

VII - valorização do profissional da educação escolar; [...]

- garantia de padrão de qualidade;

- valorização da experiência extra-escolar;

- vinculação entre a educação escolar, o trabalho e as práticas sociais.

- consideração com a diversidade étnico-racial. (Incluído pela Lei $\mathrm{n}^{\mathrm{o}}$ 12.796, de 2013)

- garantia do direito à educação e à aprendizagem ao longo da vida. (Incluído pela Lei nº 13.632, de 2018)

A Constituição Federal de 1988 , em seu artigo $205^{19}$, ressalta e reforça a importância da educação para o pleno desenvolvimento do cidadão e qualificação para o trabalho, bem como o dever do Estado de promover e incentivar o ensino.

Fácil perceber que a atividade educacional recebe amparo especial do Estado, sendo assunto constitucionalmente previsto e garantido a todos os cidadãos - direito à educação. Portanto, totalmente justificável a exceção prevista no Decreto $\mathrm{n}^{\circ}$ 9.235/2017 em assegurar a manutenção dos vínculos diretos dos professores com as Instituições de Ensino Superior (IES), proibindo a terceirização da atividade finalística educacional, vale dizer, atividade docente.

\footnotetext{
${ }^{19}$ Art. 205. A educação, direito de todos e dever do Estado e da família, será promovida e incentivada com a colaboração da sociedade, visando ao pleno desenvolvimento da pessoa, seu preparo para o exercício da cidadania e sua qualificação para o trabalho.
} 
Reforçando a importância do vínculo empregatício direto do professor, Idilvan Alencar, presidente do Conselho Nacional de Secretários de Educação (Consed), esclarece, citando a situação nas escolas públicas:

\begin{abstract}
Pela natureza das escolas públicas, é muito importante o vínculo efetivo dos professores para que seja possível o contínuo processo de formação em serviço, motivação para atuar em todo o território nacional entre outros fatores que tornam o fortalecimento da carreira de docente estratégica para garantir uma educação de qualidade. ${ }^{20}$
\end{abstract}

A formação acadêmica no Brasil é de extrema importância não apenas para a economia do país ou mesmo necessidade de trazer maior dinâmica ao mercado de trabalho (fatores, dentre outros, que motivam a defesa da terceirização), a educação atende a valores maiores, mais complexos e profundos, alcança a formação humanística do cidadão. Desse modo, a não vinculação dos professores às Instituições de Ensino Superior coloca em risco a efetividade da educação, devido à importância do acompanhamento do desenvolvimento do discente.

A incompatibilidade da terceirização da atividade docente não se verifica apenas no ensino superior, mas também e, sobretudo, no ensino fundamental e médio, enfim, em todos os níveis da formação educacional de uma pessoa. No entanto, a vedação expressa no artigo 72 , do Decreto $n^{\circ}$ 9.235/2017, se limita ao ensino superior, o que abre espaço para questionamento sobre a aplicação da mesma proibição para os demais níveis da educação.

Nesse sentido, é possível defender o entendimento de que as novas disposições sobre terceirização da atividade-fim trazidas pela Reforma Trabalhista prejudicam a atividade docente em diversos setores, devido às desigualdades salariais que poderiam ocorrer entre os terceirizados que exercem sua atividade no estabelecimento do contratante e os professores diretamente contratados pela instituição de ensino para exercer exatamente a mesma atividade, tal diferença salarial fere o princípio constitucional da igualdade.

Por outro lado, em regra, a terceirização gera grande rotatividade de profissionais no mercado, esta constante troca de professores prejudica

\footnotetext{
${ }^{20}$ TOKARNIA, Mariana - Repórter da Agência Brasil Brasília. Especialistas temem queda de concursos públicos na educação após terceirização. Publicado em 27/03/2017 - 17:08. Disponível em: http://agenciabrasil.ebc.com.br/educacao/noticia/2017-03/especialistas-temem-reducao-de-concursos-naeducacao-apos-lei-da. Acesso em 25 ago 2018.
} 
o processo de aprendizagem dos alunos, que não terão seu acompanhamento constante de evolução acadêmica.

As características mencionadas são vistas de certa forma como uma precarização das relações de trabalho, devida à importância econômica trazida para a atividade docente desenvolvida, deixando de lado a didática educacional, restando aos discentes evidentes prejuízos em sua formação, e aos professores a desvalorização da atividade docente e consequente desestímulo à carreira.

De todo modo, a terceirização efetivada na atividade docente relativa ao ensino superior é considerada ilegal por expressa vedação legal.

Sobre terceirização ilegal o TST proferiu decisão esclarecendo:

RECURSO DE REVISTA. TERCEIRIZAÇÃO ILÍCITA. DANO MORAL COLETIVO. CONFIGURAÇÃO 1. A iterativa, notória e atual jurisprudência do TST se consolidou no sentido de que a terceirização ilícita de mão-de-obra configura dano que transcende às esferas jurídicas dos empregados diretamente envolvidos e alcança a coletividade de trabalhadores, bem como a estrutura social de proteção ao emprego. 2. A burla à regular relação de emprego mediante a intermediação de mão-deobra visa o "barateamento" de custos de produção, em face da diminuição de direitos e precarização das condições e trabalho. Tais situações trazem à evidência a prática de dumping social, pois acrescenta vantagem indevida ao patrimônio das empresas que praticam o ilícito em relação às demais que atuam sob o crivo da legalidade. 3. Caso em que as reclamadas atuaram como meras intermediadoras de mão-de-obra, prestada em atividades-fim das empresas tomadoras, as quais, por suas vezes, exerciam subordinação direta sobre os empregados terceirizados. 4. Dano moral coletivo configurado. 5. Recurso de revista das Reclamadas de que não se conhece. (RR - 864-36.2013.5.03.0014, Relator Desembargador Convocado: Altino Pedrozo dos Santos, Data de Julgamento: 03/04/2018, $7^{\text {a }}$ Turma, Data de Publicação: DEJT 06/04/2018)

A vedação da terceirização da atividade finalística educacional foi bem vista devido as grandes mudanças que tal questão traria para o setor educacional do Brasil, que deve ser tratado com mais atenção pelo Estado, por ser a base do país e direito previsto constitucionalmente, devendo oferecer sempre da melhor forma a educação a todos os cidadãos.

\section{$5 \quad$ CONCLUSÃO}


A utilização do instituto da terceirização no Brasil e análise das novas disposições trazidas pela Reforma Trabalhista, representada pela Lei $\mathrm{n}^{\mathrm{o}} 13.467 / 2017$, demonstra a ampliação do uso da terceirização da prestação de serviços com a possibilidade de terceirizar também serviços relacionados à atividade-fim do contratante ou tomador dos serviços.

A discussão jurídica sobre a constitucionalidade das alterações legais sobre a terceirização trazidas pela Lei $n^{\circ}$ 13.429/2017 e, posteriormente, pela Lei n ${ }^{\circ} 13.467 / 2017$ foi esvaziada por decisão do STF que julgou constitucional a terceirização independente da atividade do contratante, validando, portanto, a terceirização de atividade-fim do tomador de serviços.

Em sentido contrário ao alargamento das hipóteses válidas de terceirização, o artigo 72, do Decreto ${ }^{\circ}$ 9.235/2017, veda a terceirização da atividade finalística educacional, prevendo severas penalidades para as Instituições de Ensino Superior que optarem pela terceirização do corpo docente.

Desse modo, no que tange a atividade docente desenvolvida no ensino superior, a terceirização é ilícita.

A restrição é vista de forma positiva pela comunidade acadêmica, tendo em vista que a terceirização da docência coloca em risco o direito à educação previsto constitucionalmente. Importante destacar que não se trata de simples direito à educação e sim do direito à educação de qualidade.

O Decreto supracitado retira a atividade educacional da mira da terceirização irrestrita, mantendo assim o corpo docente diretamente vinculado às Instituições de Ensino Superior, o que garante maior segurança para o melhor desenvolvimento acadêmico dos alunos de ensino superior no Brasil.

\section{REFERÊNCIAS}

BARROS, Alice Monteiro de. Curso de direito do trabalho. 10. ed. - São Paulo: LTr, 2016.

BRASIL. Lei no 13.429/2017. Disponível em: http://www.planalto.gov.br/ccivil_03 /_ato20152018/2017/lei/L13429.htm 
BRASIL, Lei nº 6.019/1974. Disponível em: http://www.planalto.gov.br/ccivil_03/ LEIS/L6019.htm.

MARTINS, Sergio Pinto. Direito do trabalho. 30. ed. - São Paulo: Atlas, 2014.

MENDONÇA, A.S. et al. Aspectos gerais da terceirização e quarteirização: um estudo com funcionários terceirizados. Revista acadêmica da Faculdade Fernão Dias, Osasco, n. 11, p. 122, fev. 2017.

OLIVEIRA, Mariana e BARBIÉRI, Luiz Felipe, TV Globo e G1, Brasília 22/08/2018 17h48. Relatores no STF, Barroso e Fux votam por liberar terceirização em atividades-fim. Disponível em: https://g1.globo.com/ politica/noticia/2018/08/22/relator-no-stf-barroso-vota-por-liberarterceirizacaoem-atividade-fim.ghtml. Acesso em 23 ago. 2018

POLONIO, Wilson Alves. Terceirização: aspectos legais, trabalhistas e tributários. São Paulo: Atlas, 2000.

SÜSSEKIND, Arnaldo. Instituições do direito do trabalho. 21. ed. Vol I. Editora LTr, 2003.

TOKARNIA, Mariana - Repórter da Agência Brasil Brasília. Especialistas temem queda de concursos públicos na educação após terceirização. Publicado em 27/03/2017 - 17:08. Disponível em: http://agenciabrasil.ebc.com.br/educacao/ noticia/2017-03/especialistastemem-reducao-de-concursosna-educacao-apos-lei-da. Acesso em 25 ago 2018.

TOLEDO FILHO. Manoel Carlos. Nova lei impede terceirização permanente da atividadefim. Disponível em: https://www.anamatra.org.br/artigos/25167-nova-lei-impedeterceirizacao-permanenteda-atividade-fim. Acesso em 22 ago. 2018. 